\title{
The utility of the standardized uptake value, metabolic tumor volume and total lesion glycolysis as predictive markers of recurrent breast cancer
}

\author{
A. S. Fathinul Fikri ${ }^{*}$ (D, E. Y. Chong ${ }^{1}$ and A. H. Syafrina ${ }^{2}$
}

\begin{abstract}
Background: Breast cancer is the second leading cancer killer of women globally. An early measure utilizing a noninvasive molecular marker for predicting cancer aggressiveness is important to better manage the patient and to avert early disease progression. We aimed to determine whether metabolic tumor volume (MTV) and total lesion glycolysis (TLG) are able to predict risk in high TNM tumor staging and the need for the appropriate treatment in breast cancer patients. This is a retrospective study of confirmed breast cancer patients who underwent neoadjuvant, local and adjuvant treatment and follow-up. The ${ }^{18} \mathrm{~F}-\mathrm{FDG}$ PET/CT study for initial staging was performed, and metabolic parameters (MTV, TLG, SUVmax mean) were analyzed. Spearman correlation was used to assess correlations between metabolic parameters and clinicopathological factors with TNM staging and treatment intention. SUVmean, wbMTV and wbTLG were analyzed to predict the dichotomization of patient endpoint for low (stage I and II) and high (stage III and IV) TNM stage.

Results: Twenty-six patients (4 low stage, 22 high stage) with a mean age of $51.8 \pm 11.8$ years with confirmed breast cancer underwent ${ }^{18} \mathrm{FFDG}$ PET/CT. The MTV and TLG parameters in the tumor ( $T$ ) were significantly correlated with the TNM stage $(P<0.050)$; the SUVmax mean $(4.18 \pm 1.68 \mathrm{~g} / \mathrm{dl})$, wbMTV mean $\left(404.68 \pm 558.02 \mathrm{~cm}^{3}\right)$ and wbTLG $(1756.55 \pm 2432.11 \mathrm{~g})$ differed significantly in the high versus low TNM staging with the best predictive cut-off value of SUVmax mean $(3.55 \mathrm{~g} / \mathrm{ml}, p<0.05)$, wbMTV $\left(20 \mathrm{~cm}^{3}, p<0.05\right)$ and wbTLG $(130 \mathrm{~g}, p<0.05)$ when these values were exceeded. Only wbTLG $(130 \mathrm{~g}, p<0.05)$ showed significance difference in treatment intention.

Conclusions: In this study, the metabolic parameters SUVmax mean, MTV and TLG showed potential good relationships with TNM staging. TLG was the only marker that influenced the treatment intention in predicting breast cancer aggressiveness.
\end{abstract}

\section{Background}

The global cancer statistics for 2012 show that one out of four of all cancer cases and 15\% of all cancer deaths among females are due to breast cancer [1]. Referring to a locally conducted survey, the Malaysian National Cancer

\footnotetext{
*Correspondence: ahmadsaadff@gmail.com

${ }^{1}$ Centre of Diagnostic Nuclear Imaging, Faculty of Medicine and Health Sciences, Universiti Putra Malaysia, 43600 Serdang, Selangor, Malaysia
} Full list of author information is available at the end of the article
Registry (NCR) (2012-2016) reported that there were $51,505(44.7 \%)$ new cancer cases diagnosed in men and $63,733(55.3 \%)$ in women during this period. This survey also found that among the entire female breast cancer cohort who underwent staging, approximately $80 \%$ of them were at stage II and above [2]. The most crucial parameters for recurrent breast cancer are disease restaging at the time of diagnosis and receptor status [1].

Hybrid imaging, i.e., positron emission tomography combined with computed tomography (PET/CT), has 


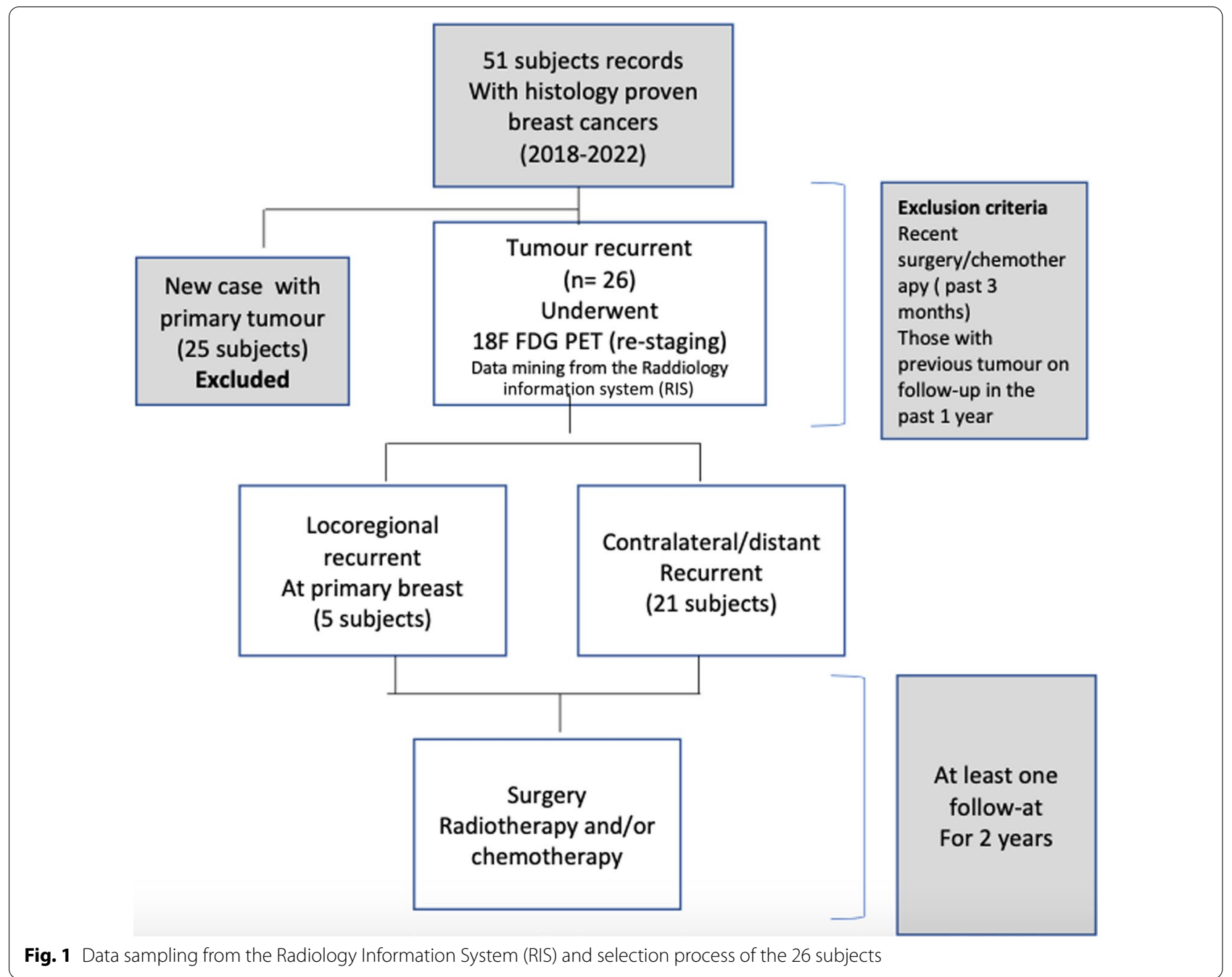

been the focus of the medical imaging community in recent years for determining the staging and follow-up of various malignancies, including breast cancer [3,4]. The improved accuracy of TNM staging by PET/CT is due to the ability of conventional imaging modalities to provide information on metabolic activity early at the cellular level [5]. Tissue metabolic activity utilizing the $3 \mathrm{D}$ volumetric tumor volume, i.e., wbTLG and wbMTV, can be quantified using ${ }^{18} \mathrm{~F}$-FDG PET-CT. The quantitative information provided indicates the functional state of tumor cells [6].

To date, multiple risk factors associated with breast cancer have been identified, but the exact etiology remains a mystery. Moreover, no definite preventive strategy has been established to reduce the incidence of breast cancer or cancer-related morbidity and mortality [7]. Therefore, in this study, we aimed to discover the effect of the use of metabolic markers for predicting recurrent breast cancer on TNM staging and treatment outcome $[8,9]$.

\section{Methods}

This study was primarily aimed at discovering the usefulness of the metabolic markers of ${ }^{18} \mathrm{~F}$ FDG PET-CT in predicting disease outcomes. The study was approved by the national ethics committee. This was a retrospective study (2018-2020) with secondary data analysis. Blinded sampling was carried out on the clinical database of 51 patients who were referred to the endocrinology clinic with a proven histological biopsy of breast cancer. Only 26 patients with follow-up at the clinic for re-staging on ${ }^{18}$ F FDG PET-CT who had at least more than 1 year of disease-free progression were included. All patients had confirmed histology for the recurrent tumor. Twenty-five patients that were new cases were excluded. Other exclusion criteria included patients with diabetes mellitus or 


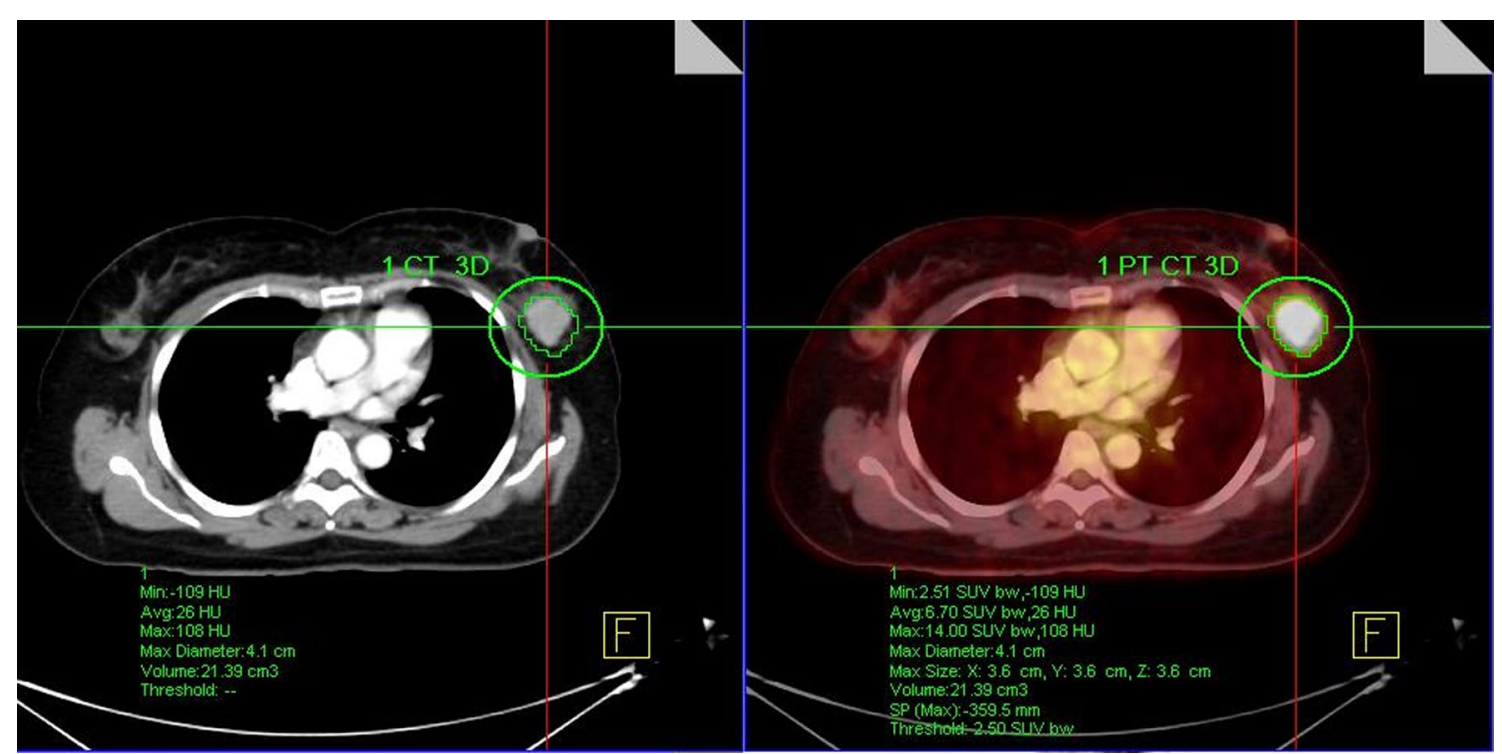

Fig. 2 Fifty-six-year-old female, post-menopausal with recurrent primary left breast carcinoma. Axial CT (left) shows an enhanced left breast mass with the correlated FDG-avid mass on the fused PET-CT image (right), SUVmax $14.00 \mathrm{~g} / \mathrm{dl}$. The FDG avidity of the lesion is more than that of the mediastinal blood pool

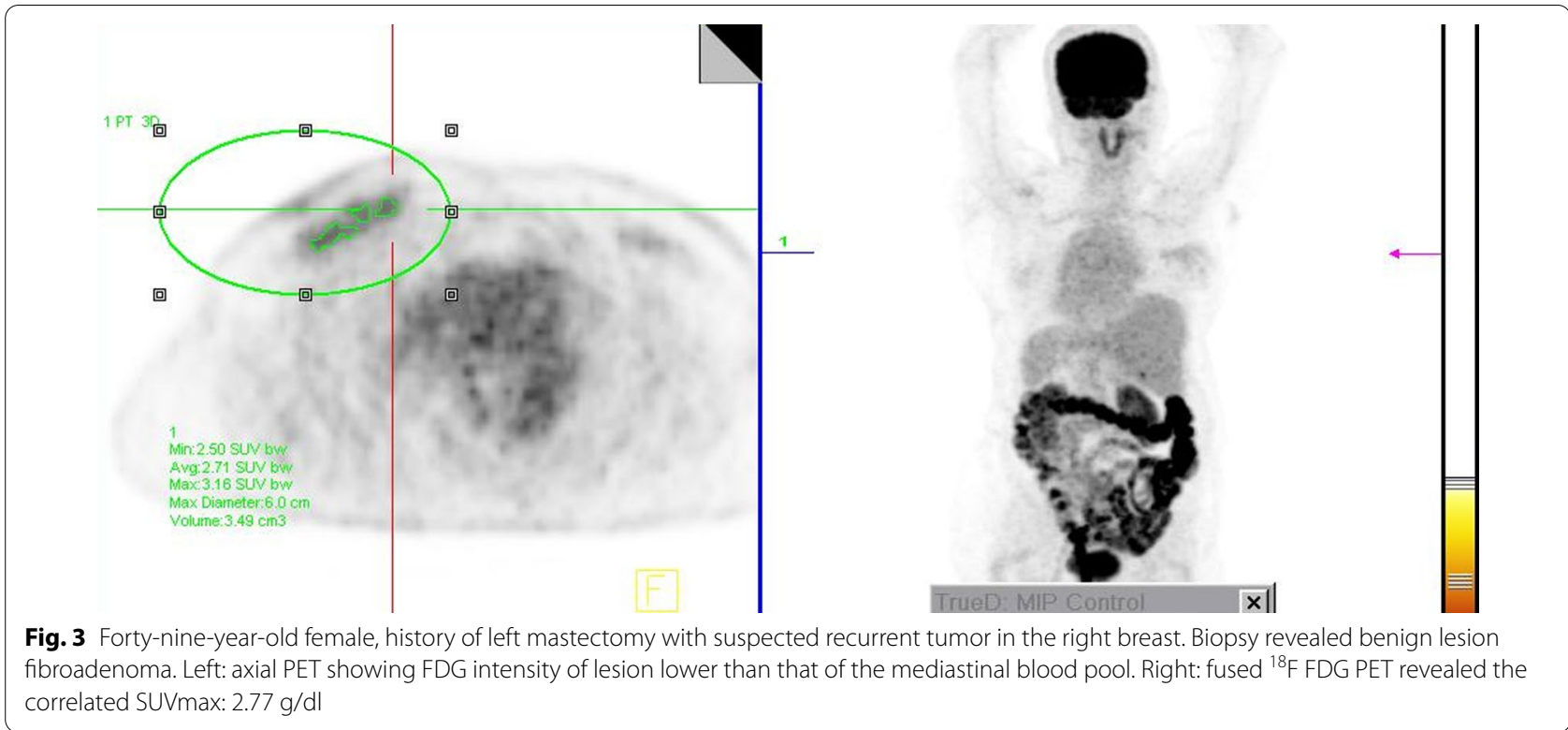

poor serum glucose control who underwent ${ }^{18}$ F FDG PET CT (glucose level of more than $10 \mathrm{mmol} / \mathrm{L}$ ), very poor renal function (blood urea level of more than $15 \mathrm{mg} / \mathrm{dl}$ ), concomitant illness such as infection, sepsis or inflammatory process, lack of follow-up data or demise. All patients were followed-up for at most 2 years to evaluate the treatment response and for prognostication (Fig. 1). The subjects were dichotomized into groups regarding TNM stage (high versus low) and treatment intention (yes versus no). The treatment intention was defined as whether the patient had no chemo-radiotherapy with/ without surgery (no) or had chemo-radiotherapy with/ without surgery (yes).

Whole-body ${ }^{18} \mathrm{~F}$-FDG PET/CT scans were performed using a Discovery 610, 16 slice MDCT, with a BGO crystal PET camera. Instructions were given to patients to fast for at least $6 \mathrm{~h}$ prior to ${ }^{18} \mathrm{~F}-\mathrm{FDG}$ intravenous injection $(5.2 \mathrm{MBq} / \mathrm{kg})$. Blood glucose was monitored and was 


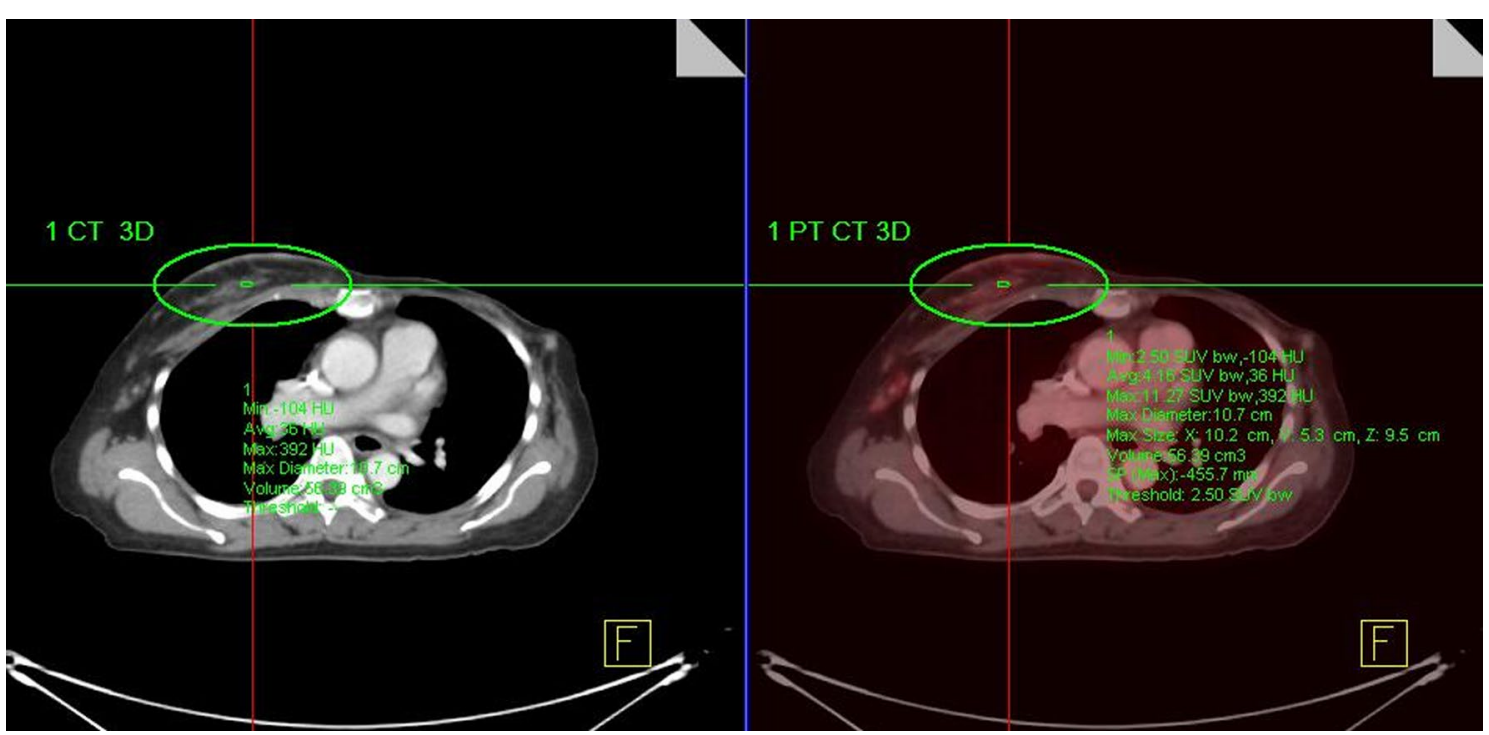

Fig. 4 Forty-five-year-old female, history of left mastectomy with suspicious right nodule noted on ultrasound. A small subcentimeter density lesion (left) is seen without FDG-avidity on the correlated fused ${ }^{18} \mathrm{~F} \mathrm{FDG} \mathrm{PET-CT} \mathrm{(right).} \mathrm{Biopsy} \mathrm{was} \mathrm{negative} \mathrm{for} \mathrm{malignancy}$

Table.1 Qualitative assessment of the lesions on ${ }^{18} \mathrm{~F} \mathrm{FDG} \mathrm{PET-CT}$

\begin{tabular}{lll}
\hline Reference FDG uptake & $\begin{array}{l}\text { Lesion FDG-avidity lower than mediastinal blood pool / } \\
\text { liver (SUVmax less than or equal to } \mathbf{2 . 5} \mathbf{g} / \mathbf{d l} \text { ) }\end{array}$ & $\begin{array}{l}\text { Lesion avidity higher than mediastinal } \\
\text { blood pool/liver (SUVmax more than to } \\
\mathbf{2 . 5} \mathbf{~ g / d l )}\end{array}$ \\
\hline $\begin{array}{ll}\text { Mediastinal blood pool (8) } \\
\text { Liver (9) }\end{array}$ & Negative lesion & $\begin{array}{l}\text { Positive lesion } \\
\text { Negative lesion }\end{array}$ \\
\hline
\end{tabular}

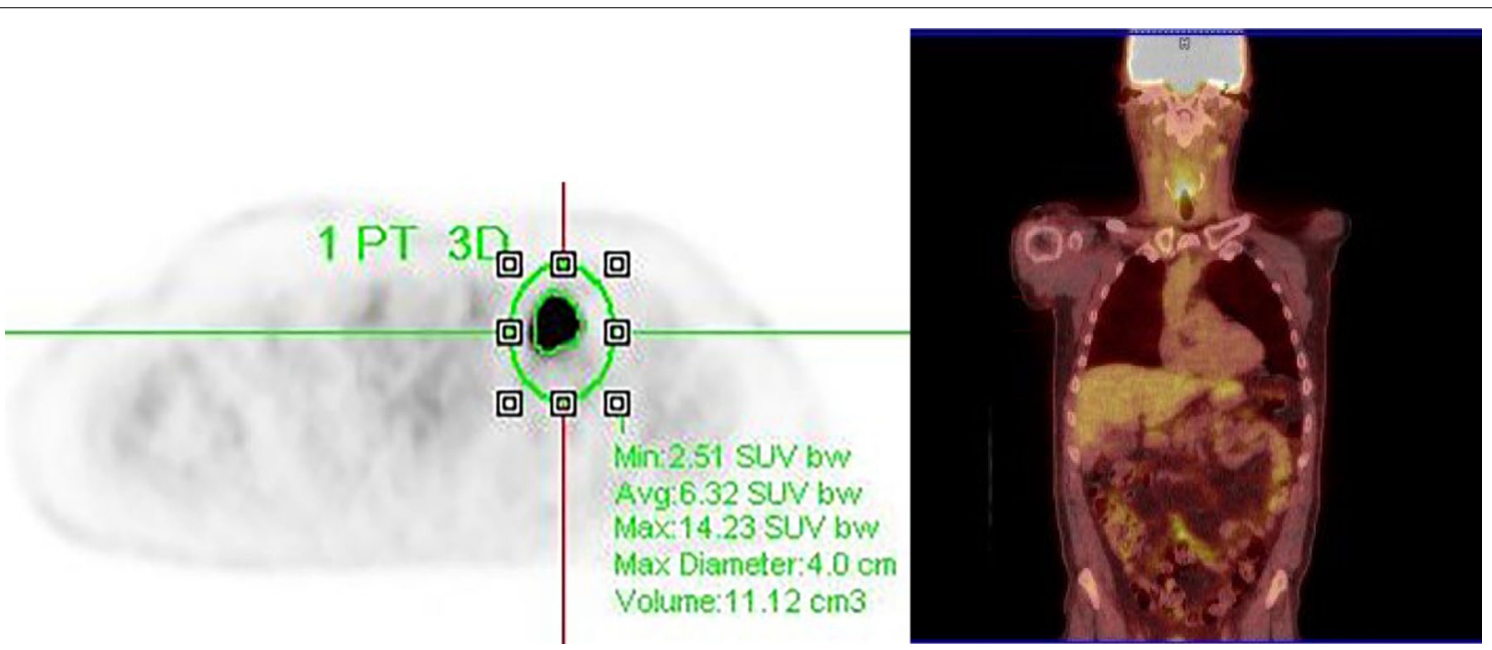

Fig. 5 Left: Measurement of a hypermetabolic lesion within the VOI. Right: Hot-body color standardization (FDG uptake: Grade 4: Brain, Grade 3: Liver, Grade 2: mediastinal blood pool and grade 1 background)

below $10.0 \mathrm{mmol} / \mathrm{L}$ for all patients prior to the time of ${ }^{18} \mathrm{~F}$-FDG injection. Imaging was started at $60 \mathrm{~min}$ after ${ }^{18}$ F-FDG injection, covering the area from base of skull to mid-thigh using the following protocol: PET images acquired in list mode acquisition, 2 min per bed position. The CT scan was performed first before PET, and 
Table.2 Patient characteristics $(n=26)$

\begin{tabular}{ll}
\hline Characteristic & $\boldsymbol{n}$ (\%) \\
\hline Age (years) & \\
$<50$ years & $11(42.3 \%)$ \\
$>50$ years & $15(57.7 \%)$ \\
Menopause & \\
No & $11(42.3 \%)$ \\
Yes & $15(57.7 \%)$ \\
Obesity & \\
Normal (BMI 18.5-24.9) & $20(76.9 \%)$ \\
Obese (BMI 25$)$ & $6(23.1 \%)$ \\
Recurrent tumor lesions & \\
Patient basis & $26 / 26$ \\
Lesion basis & \\
Locoregional recurrent & 5 \\
Contralateral breast recurrent & 16 \\
Lymph node metastasis & \\
Right axillary & 21 \\
Left axillary & 6 \\
Distant metastasis & 159 \\
Treatment intention & \\
Yes & \\
No & \\
7th AJCC breast cancer TNM stage & \\
Low stage (stage I and II) & $17(65.4 \%)$ \\
High stage (stage III and IV) & \\
\hline
\end{tabular}

${ }^{*}$ Descriptive statistics; $\mathrm{n}=$ frequency; $\%=$ percentage

the CT image data were used to automatically position the patient for PET acquisition. All images were reconstructed using an iterative algorithm and were transferred to a dedicated workstation (SyngoVia) and analyzed using syngo True-D software. Every hypermetabolic lesion was selected, and a volume of interest (VOI) placed manually over the visible area of a target lesion on each PET image (Figs. 1, 2, 3, 4).

\section{Image evaluation}

Retrieved images were read by a radiologist with more than 10 years of working exposure. The radiologist was blinded to the previous PET-CT reporting results and the clinical diagnosis of the patients. A positive lesion on PET-CT (Fig. 1) was determined when the uptake of the lesion in question appeared higher than the FDG uptake in the background (mediastinal blood pool in the thorax or liver uptake in the abdomen) $[8,9]$. A negative lesion was determined when the suspected lesion had lower FDG-avidity than the background (Fig. 2). Standardization of every PET reading was performed to establish consistent image quality by adjusting the qualitative parameter based on the FDG physiological accumulation
Table.3 Correlation between mean SUVmax and TNM stage

\begin{tabular}{lll}
\hline & TNM stage & Mean SUV max \\
\hline $\begin{array}{l}\text { Spearman's rho } \\
\text { TNM stage }\end{array}$ & \\
Correlation coefficient & 1.000 & $0.469^{*}$ \\
Sig. (two-tailed) & - & 0.016 \\
$N$ & 26 & 26 \\
Mean SUVmax & & \\
Correlation coefficient & $0.469^{*}$ & 1.000 \\
Sig. (two-tailed) & 0.016 & - \\
$N$ & 26 & 26 \\
\hline${ }^{*}$ Correlation is significant at the 0.05 level (two-tailed) &
\end{tabular}

in the body (Fig. 3). These parameters were used based on the PET qualitative criteria-Rod's Rule [9]. Positive lesions were also determined as having an SUVmax (g/ dl) of more than 2.5 as a standard for the semiquantitative measurement, and therefore we recorded the mean of SUVmax for all lesions based on the TNM staging (Figs. 1, 2) (Table 1).

\section{Semiquantitative analysis}

The summation of all the lesion volumes of a patient was defined as whole body MTV (wbMTV). The whole body TLG (wbTLG) was calculated as the sum of the TLG values for each lesion in one patient [10] (Fig. 5). All data were transferred for statistical analysis.

\section{Data analysis}

Statistical analysis was carried out using Statistical Analysis of Social Sciences System (SPSS) Version 23. Data are presented as the mean and standard deviation (SD) of numerical data such as age, mean SUV, whole-body MTV and whole-body TLG. Spearman correlations were performed to test correlations between nonparametric variables. Cut-off values for mean SUVmax, whole-body TLG and whole-body MTV were determined using receiver operating characteristic (ROC) curve analysis. Treatment intention was used as a dependent variable in the ROC curve analysis. Pearson Chi-squared tests and Fisher's exact tests were performed to test the association between two independent categorical variables. A $p$ value less than $0.05(<0.05)$ was taken to indicate statistical significance. The dependent variables in this study include the TNM staging of breast cancer, as well as treatment intent. The independent variables in this study include ${ }^{18} \mathrm{~F}$-FDG PET/ CT derived metabolic parameters such as mean SUV, wbMTV and wbTLG and clinicopathological parameters such as age, menopause status, BMI and obesity status. 


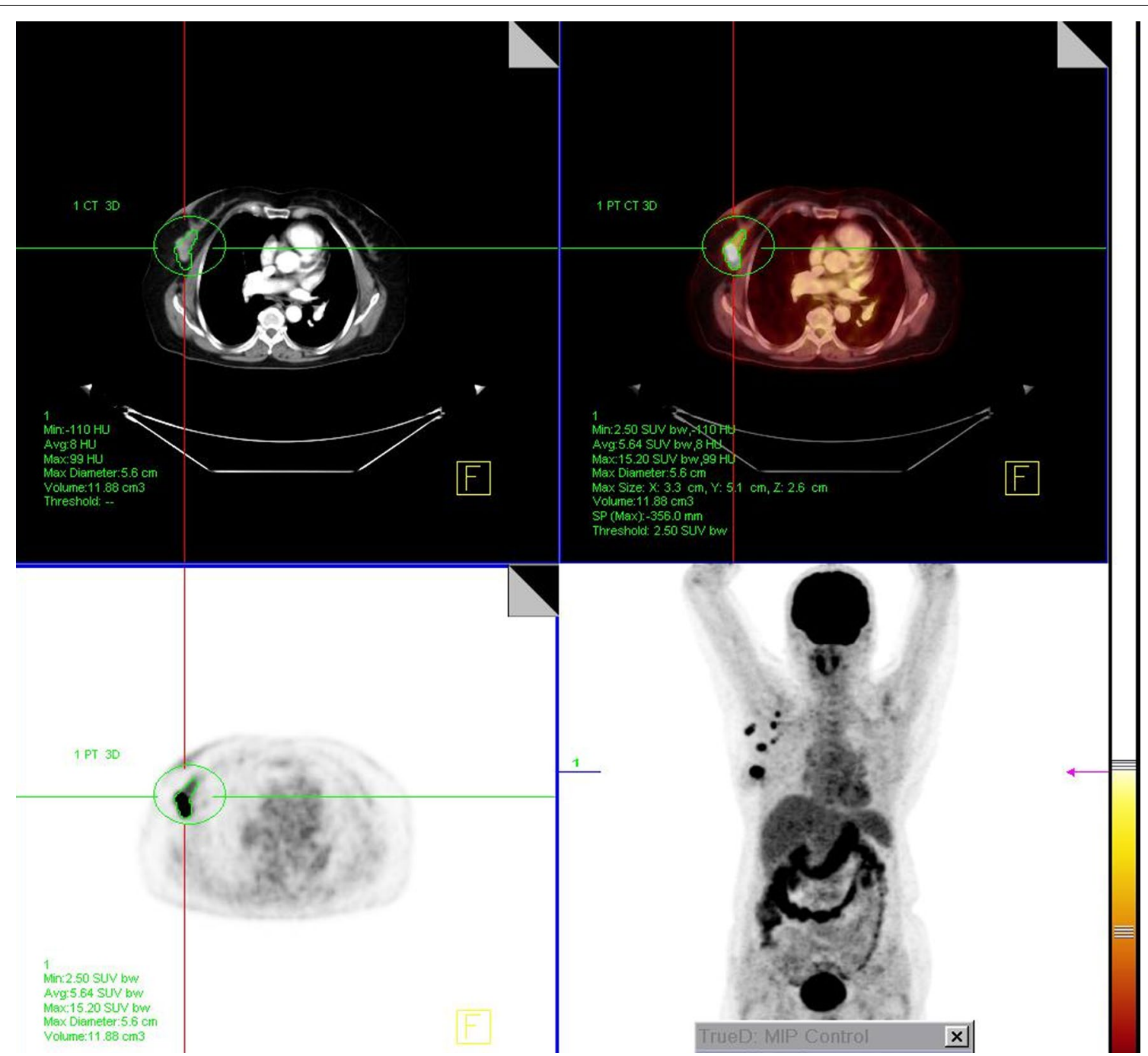

Fig. 6 Axial CT, PET and MIP Fused PET-CT. Patient with recurrent locoregional tumor (SUVmax: 15.20) and ipsilateral lymph node metastasis (stage IIIB)

\section{Results}

A total of 26 subjects were included in this study. For the purpose of this study, all the selected patients were dichotomized according to their clinicopathological status and metabolic parameter uptake value of ${ }^{18} \mathrm{~F}$-FDG $\mathrm{PET} / \mathrm{CT}$. On a per lesion basis, there were 21 recurrent lesions in the breast (mean SUVmax: $4.17 \pm 1.67$ ), 27 lesions in the axillary lymph nodes (mean SUVmax: $4.39 \pm 1.69)$ and 159 recurrent lesions at distant sites (mean SUVmax: $3.52 \pm 1.08$ ). All patients underwent surgical treatment and some of them $(17 / 26,65.4 \%)$ underwent additional chemo- and/or radiotherapy prior to the study. Among the 26 patients, the majority of them $(22 / 26,84.6 \%)$ were classified as high stage (stage III or IV), while the remaining $4 / 22(15.4 \%)$ were low stage (stage I or II). Table 2 summarizes the demographic data, treatment intention and 7th AJCC breast cancer TNM staging of the patients at the time of image acquisition.

\section{Correlation between obesity, menopause and TNM stage}

The correlations between obesity, menopause and breast cancer TNM stage of all patients $(n=26)$ were analyzed. Menopause and obesity were weakly inversely correlated with TNM stage (Fig. 6). However, these parameters were not significantly correlated $(p>0.05)$.

\section{Correlation of mean SUVmax with TNM stage}

There was a strong correlation between mean SUVmax and TNM stage in all patients $(n=26)$ (Table 3$)(p<0.05)$. 


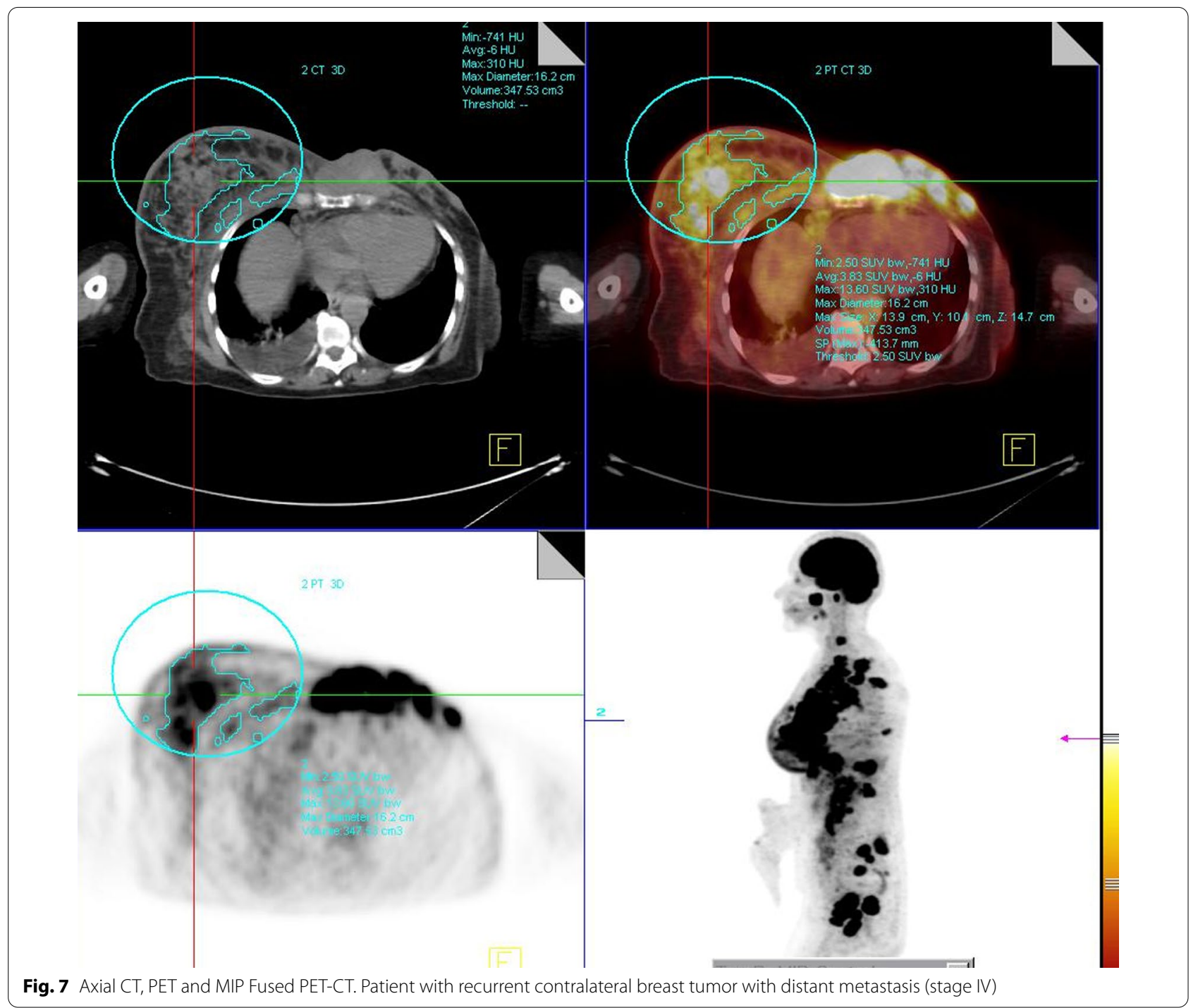

This means that a high mean SUVmax $(4.18 \pm 1.68 \mathrm{~g} / \mathrm{dl})$ was associated with a high TNM stage (Fig. 7).

The mean SUVmax was plotted on a receiver operating characteristic (ROC) curve and analyzed. The area under the curve (AUC) was 0.706, with a 95\% confidence interval (CI) of 0.503-0.909 (Fig. 8).

The optimum value of mean SUVmax was determined to be $3.55 \mathrm{~g} / \mathrm{ml}$ (sensitivity 78\%, specificity 59\%). There were significantly more patients (Fig. 9) with a high TNM stage $(14,53.8 \%)$ who had a mean SUVmax higher than $3.55 \mathrm{~g} / \mathrm{ml}$, compared to the low TNM stage group $(0,0 \%)$ $(p<0.05$; Fisher's exact test) (Table 4$)$.
Whole body metabolic tumor volume (wbMTV)

The wbMTV (mean $404.68 \mathrm{~cm}^{3}$ ) and TNM were strongly and significantly correlated $(p<0.05)$. This means that a high wbMTV $\left(404.68 \pm 558.02 \mathrm{~cm}^{3}\right)$ was associated with a high TNM stage (Table 5).

As shown in Table 6, there were significantly more patients with a high TNM stage $(14,53.8 \%)$ who had a wbMTV of more than $20 \mathrm{~cm}^{3}$, compared to the low TNM stage group $(8,30.8 \%)(p<0.05$; Fisher's exact test).

\section{Correlation of wbMTV and treatment intention}

wbMTV and treatment intention were poorly correlated in the 26 patients $(p>0.05)$ (Table 7). 


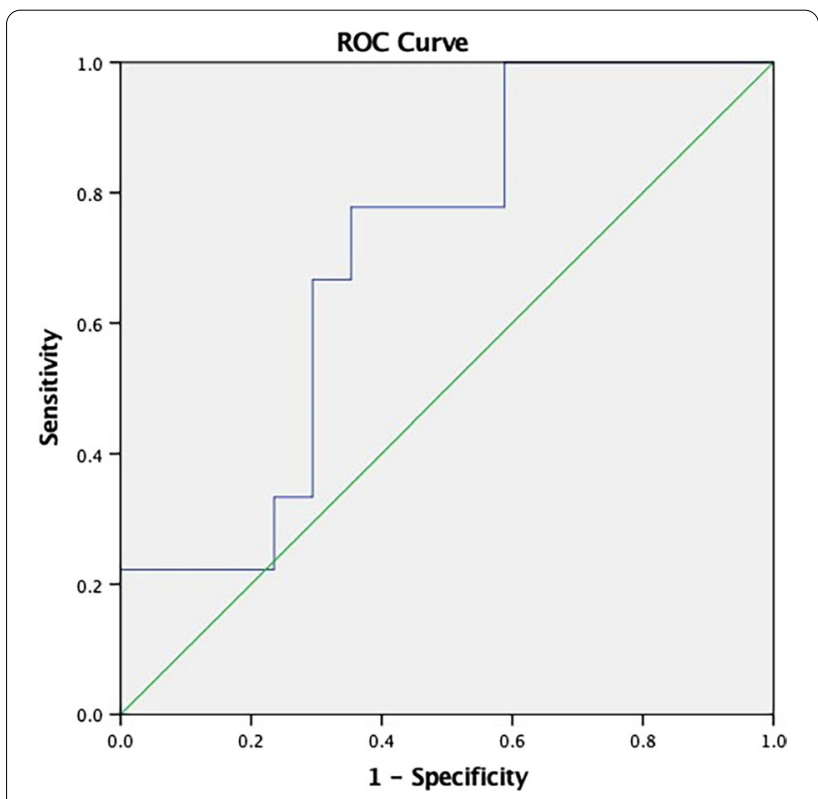

Fig. 8 Receiver operating characteristic curve (ROC)

\section{Correlation of wbTLG with TNM stage}

The correlation of wbTLG with the TNM stage of 26 patients is shown in Table 8. The wbTLG was strongly and significantly correlated with TNM stage $(p<0.05)$. This means that a higher wbTLG value (mean: $1756.55 \pm 2432.11 \mathrm{~g}$ ) was associated with a high TNM stage.

However, there was a poor correlation between TNM staging and treatment intent $(p>0.05)$. The wbTLG was plotted on the receiver operating characteristic (ROC) curve and analyzed. The area under the curve (AUC) was 0.634 , with a $95 \%$ confidence interval (CI) of $0.411-0.857$ (Fig. 7).

Table.4 Outcome according to mean SUVmax of $3.55 \mathrm{~g} / \mathrm{ml}$ with TNM stage

\begin{tabular}{llll}
\hline & $\begin{array}{l}\text { Mean } \\
\text { SUVmax }<3.55\end{array}$ & $\begin{array}{l}\text { Mean } \\
\text { SUVmax }>3.55\end{array}$ & pvalue \\
\hline $\begin{array}{l}\text { TNM stage * mean SUVmax } \\
\text { of } 3.55 \mathrm{~g} / \mathrm{m} / \text { cross-tabula- } \\
\text { tion }(n=26)\end{array}$ & & \\
TNM stage & & & \\
Low & & & \\
Count & 4 & 0 & $0.033^{*}$ \\
$\%$ of total & $15.4 \%$ & $0.0 \%$ & \\
High & & & \\
Count & 8 & 14 & \\
$\%$ of total & $30.8 \%$ & $53.8 \%$ & \\
\hline
\end{tabular}

*Correlation is significant at the 0.05 level (two tailed)
Table.5 Correlation between wbMTV and TNM stage

\begin{tabular}{lll}
\hline & TNM stage & wbMTV \\
\hline $\begin{array}{l}\text { Spearman's rho } \\
\text { TNM stage }\end{array}$ & \\
Correlation coefficient & 1 & $0.469^{*}$ \\
Sig. (two-tailed) & - & 0.016 \\
$N$ & 26 & 26 \\
wbMTV & & \\
Correlation coefficient & $0.469^{*}$ & 1 \\
Sig. (two-tailed) & 0.016 & - \\
$N$ & 26 & 26 \\
\hline${ }^{*}$ Correlation is significant at the 0.05 level (two-tailed) &
\end{tabular}

The optimum value of wbTLG was determined to be $130 \mathrm{~g}$ (sensitivity $89 \%$, specificity $59 \%$ ). There were significantly more patients (Fig. 10) at a high TNM stage (15, $57.7 \%)$ who had a wbTLG more than $130 \mathrm{~g}$, compared to the low TNM stage group $(0,0.0 \%)(p<0.05$; Fisher's exact test) (Table 9).

\section{wbTLG with treatment intention}

There were significantly more patients who underwent treatment $(8,30.8 \%)$ who had a wbTLG greater than $130 \mathrm{~g}$, compared to patients without treatment $(1,3.8 \%)$ $(p<0.05$; Fisher's exact test) (Table 10).

The logistic regression model was used to determine the most potent predictive factors for TNM and treatment intention. The results indicated that there was no association between TLG, interaction between TLG and SUV, interaction between TLG and MTV and interaction between TLG, SUV and MTV with TNM staging.

\section{Discussion}

Prediction of the effect of treatment intention by the treating physician on the TNM staging is important in characterizing the cancer aggressiveness of recurrent tumors. The utility of metabolic markers measured by ${ }^{18} \mathrm{~F}$ FDG PET has taken center stage as the parameters underpin the cellular metabolic derangement caused by proliferative mitosis [10]. It is thus useful to assess the effect of prediction of these markers on treatment outcome and its association with TNM staging. In our study, despite the known association of the clinical parameters of age, menopause, BMI, obesity and metabolic parameters, there were no correlations that could have predicted TNM staging more accurately than previous studies [11, 12].

In our study, the mean SUVmax $(4.18 \pm 1.68 \mathrm{~g} / \mathrm{dl})$ was strongly correlated with the TNM stage. This finding was consistent with other studies with comparable findings, indicating that the rate of glycolytic uptake of tumor cells 


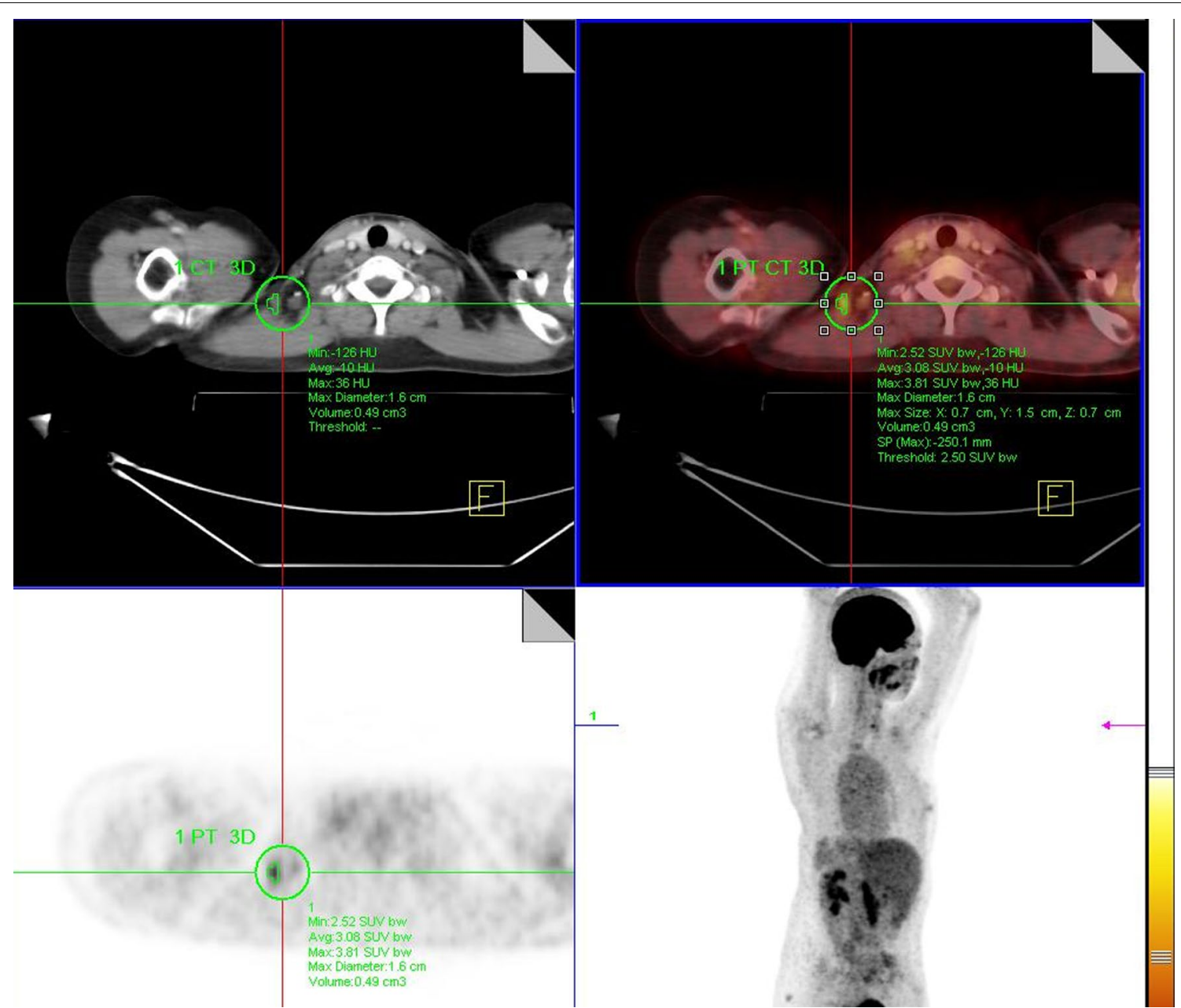

Fig. 9 Axial CT, PET and MIP Fused PET-CT. Fifty-year-old female with history of right mastectomy. There was a recurrent right supraclavicular lymph node tumor on re-staging (stage IIIC)

Table.6 Outcome according to wbMTV $20 \mathrm{~cm}^{3}$ with TNM stage

\begin{tabular}{llll}
\hline & MTV $<\mathbf{2 0}$ & MTV $>\mathbf{2 0}$ & $\boldsymbol{p}$ value \\
\hline $\begin{array}{l}\text { TNM stage }{ }^{*} \text { wbMTV 20 } \mathrm{cm}^{3} \\
\text { cross-tabulation }(n=26)\end{array}$ & & & \\
TNM stage & & & \\
Low & 4 & 0 & $0.033^{*}$ \\
Count & $15.4 \%$ & $0.0 \%$ & \\
$\%$ of total & & & \\
High & 8 & 14 & \\
Count & $30.8 \%$ & $53.8 \%$ & \\
$\%$ of total & & & \\
\hline
\end{tabular}

${ }^{*}$ Significance level $(p<0.05)$

has a strong correlation with higher staging of the disease (stage III \& IV) at diagnosis [13-15]. SUV is used as a popular predictive metabolic marker for staging and in
Table.7 Correlation between wbMTV and treatment intention

\begin{tabular}{lll}
\hline & wbMTV & $\begin{array}{l}\text { Treatment } \\
\text { intention }\end{array}$ \\
\hline $\begin{array}{l}\text { Spearman's rho } \\
\text { wbMTV }\end{array}$ & \\
Correlation coefficient & 1.000 & 0.210 \\
Sig. (two-tailed) & - & 0.303 \\
$n$ & 26 & 26 \\
\hline${ }^{*}$ Significance level $(p<0.05)$ & &
\end{tabular}

characterizing tumor cellular aggressiveness. Nevertheless, its utility falls short because of variability in its values in different tumor lines and technical factors [16]. The SUV uptake of ${ }^{18} \mathrm{~F}$ FDG samples the 2D tumor dimension randomly and glucose uptake, which may underestimate the true SUV value of the whole lesion [17]. Therefore, 3D 


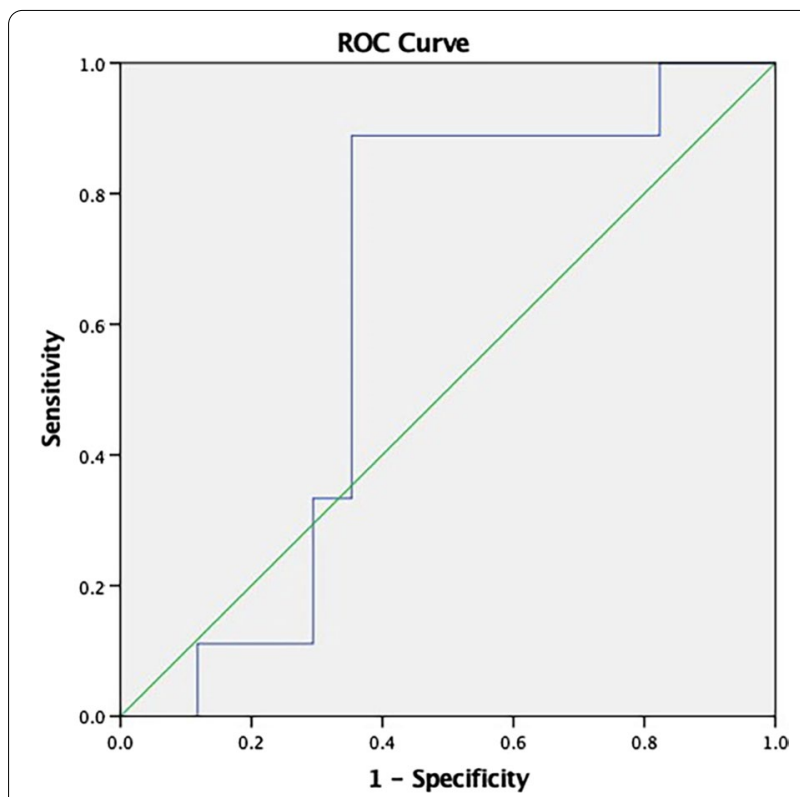

Fig. 10 ROC curve of wbTLG

volumetric assessments, i.e., wbMTV and wbTLG, could be used as potentially more accurate parameters. In this study, the mean of the wbMTV $\left(404.68 \pm 558.02 \mathrm{~cm}^{3}\right)$ and wbTLG $(1756.55 \pm 2432.11 \mathrm{~g})$ was strongly correlated with a higher TNM stage $(p<0.05)$. This was substantiated by Son et al. who found that wbMTV values in non-survivors were significantly higher than among survivors ( $424.0 \pm 683.9$ vs. $92.1 \pm 96.3 \mathrm{~cm}^{3}$, respectively; $p=0.0430)$, as were wbTLG values $(1980.9 \pm 3159.3$ vs. $444.3 \pm 459.5 \mathrm{~g}$, respectively; $p=0.0428)$ ] [10]. Another study involving 40 breast cancer patients also showed that those with an MTV $T \geq 19.3 \mathrm{~cm}^{3}$ and TLG $T \geq 74.4 \mathrm{~g}$ were 10-12 times more likely to recidivate in aggressive tumor cells when these thresholds were exceeded [18]. Correspondingly, the MTV and TLG are potentially promising in ascertaining the association between the

Table.8 Correlation between wbTLG and TNM stage

\begin{tabular}{|c|c|c|}
\hline & TNM stage & wbTLG \\
\hline \multicolumn{3}{|l|}{ Spearman's rho } \\
\hline \multicolumn{3}{|l|}{ TNM stage } \\
\hline Correlation coefficient & 1.000 & $0.469^{*}$ \\
\hline Sig. (two-tailed) & - & 0.016 \\
\hline$n$ & 26 & 26 \\
\hline \multicolumn{3}{|l|}{ wbTLG } \\
\hline Correlation coefficient & $0.469^{*}$ & 1.000 \\
\hline Sig. (two-tailed) & 0.016 & - \\
\hline$n$ & 26 & 26 \\
\hline
\end{tabular}

${ }^{*}$ Correlation is significant at the 0.05 level (two-tailed)
Table.9 Outcome according to wbTLG $130 \mathrm{~g}$ and TNM stage

\begin{tabular}{llll}
\hline & TLG $<\mathbf{1 3 0}$ & TLG $>$ 130 & p value \\
\hline $\begin{array}{l}\text { TNM stage * wbTLG 130 g } \\
\text { cross-tabulation }(n=26)\end{array}$ & & \\
TNM stage & & & \\
Low & 4 & 0 & $0.022^{*}$ \\
Count & $15.4 \%$ & $0.0 \%$ & \\
$\%$ of total & & & \\
High & 7 & 15 & \\
Count & $26.9 \%$ & $57.7 \%$ & \\
$\%$ of total & & & \\
\hline
\end{tabular}

${ }^{*}$ Significance level $(p<0.05)$

Table.10 Outcome according to wbTLG $130 \mathrm{~g}$ and treatment intention

\begin{tabular}{llll}
\hline & TLG $\leq \mathbf{1 3 0}$ & TLG $>130$ & P value \\
\hline $\begin{array}{l}\text { Treatment intention * wbTLG } \\
\text { 130 g cross-tabulation }(n=26)\end{array}$ & & & \\
$\begin{array}{l}\text { Treatment } \\
\text { No }\end{array}$ & & & \\
Count & 10 & 7 & 0.03 \\
$\%$ of total & $38.5 \%$ & $26.9 \%$ & \\
Yes & & & \\
Count & 1 & 8 & \\
$\%$ of total & $3.8 \%$ & $30.8 \%$ & \\
\hline
\end{tabular}

${ }^{*}$ Significance level $(p<0.05)$

tendency for localized tumor invasion, distant metastasis and overall survival in hypopharyngeal cancer [19-22].

The cut-off values for the mean SUVmax $(3.55 \mathrm{~g} / \mathrm{ml}$ $\mathrm{p}=0.033)$, wbMTV $\left(\geq 20 \mathrm{~cm}^{3}, p=0.033\right)$ and wbTLG $(\geq 130 \mathrm{~g}, p=0.022$ ) could potentially become good predictors of breast cancer aggressiveness. The values of these parameters are consistent with those found in another study, which reported the best cut-off values of whole-body SUVmax (20.4 g/dL, AUC 0.79, $p=0.011)$, wbMTV $\left(38.1 \mathrm{~cm}^{3}\right.$, AUC 0.81, $\left.p=0.008\right)$ and wbTLG (169.1 g, AUC 0.78, $p=0.015$ ) for predicting disease recurrence in a group of locally advanced breast cancer patients [23, 24]. A study by An et al. comprising 173 patients with invasive breast carcinoma revealed that the SUVmean $(>1.2, p=0.033)$ and $\operatorname{MTV}\left(>2.38 \mathrm{~cm}^{3}\right.$, $p=0.005$ ) values of breast tumors are statistically powerful for predicting axillary lymph node metastasis in $\mathrm{T} 1$ and $\mathrm{T} 2 / \mathrm{T} 3$ breast cancer, respectively $[25,26]$.

On another note, the noninvasive metabolic markers SUV, wbMTV and wbTLG could potentially be used as a surrogate marker to the histological findings. In our study, wbTLG (130 g) was the only potentially predictive 
marker for determining the treatment outcome. A higher wbTLG value is likely to predict more patients who may undergo systemic treatment than surgical treatment alone. Few reports in the literature have discussed the reliability of wbTLG, and our study may set a new standard for its use as a metabolic marker in evaluating breast cancer aggressiveness.

Our study has a few limitations in relation to the population at large. The number of study subjects was relatively small, which may have led to bias in determining the true values in assessing the metabolic markers as predictors of breast cancer aggressiveness. Furthermore, the study was performed retrospectively; therefore, the incremental value of ${ }^{18} \mathrm{~F}$ FDG PET_CT in evaluating the disease outcome was based on the clinical assessment of the patients' cohort, given that no post-treatment PET imaging was available [26, 27]. Finally, only one reader was assigned to read the sampled PET data which was substantiated by the quantitative SUVmax standard reference to ensure the consistency of the results.

\section{Conclusions}

In this study, the SUV, wbMTV and wbTLG were found to be potential metabolic markers predicting a high TNM stage and the treatment intention. The 3D assessment of the tumor metabolic volumes by MTV and TLG gave new insight into the reliability of the metabolic parameters to be used as predictive markers. In particular, the cut-off value points to predict the likelihood of patient be subjected to systemic therapy than surgery where wbTLG $>130 \mathrm{~g}$ being more likely to recidivate when this threshold were exceeded.

\section{Abbreviations \\ PET: Positron emission tomography; CT: Computed tomography; 18 F-FDG: 2-Deoxy-2-fluoro [18F]-D-glucose; SUV: Standardized uptake value; SUVmin: Minimum standardized uptake value; SUVmean: Average standardized uptake value; SUVmax: Maximum standardized uptake value; MTV: Metabolic tumor volume; wbMTV: Whole body metabolic tumor volume; TLG: Total lesion gly- colysis; wbTLG: Whole-body total lesion glycolysis; MRI: Magnetic resonance imaging; ROI: Region of interest; VOI: Volume of interest; HPE: Histopathologi- cal examination; SPSS: Statistical Analysis of Social Sciences System; AJCC: American Joint Committee on Cancer.}

\section{Acknowledgements}

The authors would like to thank the Executive Director and Chief Executive Officer of the KPJ Johor Specialist Hospital in granting the use of data access for the purpose of this study

\section{Authors' contributions}

All authors CEY, SAH and FFAS have approved and made substantial contributions to the conception design of the work and the acquisition. SAH contributed to the analysis and interpretation of data. All authors have read and approved the final manuscript.
Funding

There was no funding involved in the conduct of this study.

\section{Availability of data and materials}

The data is available in the author's database and accessible on specific request upon the agreement by the author.

\section{Declarations}

\section{Ethics approval and consent to participate}

All procedures involving human participants were performed in accordance with the ethical standards of the institutional committee, as well as the 1964 Helsinki Declaration and its later amendments or comparable ethical standards. This article does not contain any animal experiments. Verbal consent was obtained from all participants included in the study, and this was approved by the ethic committee (reference no: Jawankuasa Etika Universiti Putra Malaysia: JKEUPM-2019-339).

\section{Consent for publication}

Not applicable.

\section{Competing interests}

The authors declare that they have no competing interests.

\section{Author details}

${ }^{1}$ Centre of Diagnostic Nuclear Imaging, Faculty of Medicine and Health Sciences, Universiti Putra Malaysia, 43600 Serdang, Selangor, Malaysia. ${ }^{2}$ Department of Mathematics and Statistics, Faculty of Science, Universiti Putra Malaysia (UPM), 43400 Serdang, Malaysia.

Received: 21 April 2021 Accepted: 26 September 2021

Published online: 06 October 2021

\section{References}

1. Groheux D, Cochet A, Humbert O, Alberini JL, Hindié E, Mankoff D (2016) ${ }^{18} \mathrm{~F}$-FDG PET/CT for staging and restaging of breast cancer. J Nucl Med 57(S1):17S-26S

2. Azizah AM, Hashimah B, Nirmal K et al (2019) Malaysia National Cancer Registry Report (MNCR) 2012-2016, Malaysia cancer statistics, data and figure. Putrajaya: National Cancer Institute, Ministry of Health

3. Yararbas U, Avci NC, Yeniay L et al (2018) The value of 18F-FDG PET/ CT imaging in breast cancer staging. Bosn J Basic Med Sci 18(1):72-79. https://doi.org/10.17305/bjbms.2017.2179

4. Piva R, Ticconi F, Ceriani V et al (2017) Comparative diagnostic accuracy of 18F-FDG PET/CT for breast cancer recurrence. Breast Cancer Targets Therapy 9:461-471. https://doi.org/10.2147/BCTT.S111098

5. Hofman MS, Hicks RJ (2016) How we read oncologic FDG PET/CT. Cancer Imaging 16(1):1-14. https://doi.org/10.1186/s40644-016-0091-3

6. Groheux D, Cochet A, Humbert O et al (2016) (1)(8)F-FDG PET/CT for staging and restaging of breast cancer. J Nucl Med 57(Suppl 1):17S-26S. https://doi.org/10.2967/jnumed.115.157859

7. Ataollahi MR, Sharifi J, Paknahad MR, Paknahad A (2015) Breast cancer and associated factors: a review. J Med Life 8(4):6-11

8. Joo HO, Yoo IR, Kim SH, Sohn HS, Chung SK (2007) J Nucl Med 48(1):15-21

9. Hofman MS, Hicks RJ (2016) How we read oncologic FDG PET/CT. Cancer Imaging 16:35. https://doi.org/10.1186/s40644-016-0091-3

10. Fikri AS, Kroiss A, Ahmad AZ, Zanariah H, Lau WF, Uprimny C, Donnemiller E, Kendler D, Nordin AJ, Virgolini IJ (2014) Localization and prediction of malignant potential in recurrent pheochromocytoma/paraganglioma (PCC/PGL) using 18F-FDG PET/CT. Acta Radiol 55(5):631-640

11. Patrício M, Pereira J, Crisóstomo J et al (2018) Using resistin, glucose, age and BMI to predict the presence of breast cancer. BMC Cancer 18(1):1-8. https://doi.org/10.1186/s12885-017-3877-1

12. Leitner BP, Perry RJ (2020) The impact of obesity on tumor glucose uptake in breast and lung cancer. JNCl Cancer Spectrum 4(2):1-5. https://doi.org/10.1093/jncics/pkaa007

13. Chang CC, Chen CJ, Hsu WL et al (2019) Prognostic significance of metabolic parameters and textural features on 18F-FDG PET/CT in 
invasive ductal carcinoma of breast. Sci Rep 9(1):1-11. https://doi.org/ 10.1038/s41598-019-46813-5

14. Garcia Vicente AM, Soriano Castrejon A, Lopez-Fidalgo JF et al (2015) Basal (1)(8)F-fluoro-2-deoxy-D-glucose positron emission tomography/computed tomography as a prognostic biomarker in patients with locally advanced breast cancer. Eur J Nucl Med Mol Imaging 42(12):1804-1813. https://doi.org/10.1007/s00259-015-3102-x

15. Kim J, Yoo SW, Kang SR et al (2012) Prognostic significance of metabolic tumor volume measured by $18 \mathrm{~F}-\mathrm{FDG}$ PET/CT in operable primary breast cancer. Nucl Med Mol Imaging 46(4):278-285. https://doi.org/10.1007/ s13139-012-0161-9

16. Wong TZ, Khandani AH, Sheikh A (2015) nuclear medicine. Clin Radiat Oncol. https://doi.org/10.1016/B978-0-323-24098-7.00011-3

17. Taghipour M, Wray R, Sheikhbahaei S et al (2016) FDG avidity and tumor burden: Survival outcomes for patients with recurrent breast cancer. Am J Roentgenol 206(4):846-855. https://doi.org/10.2214/AJR.15.15106

18. Jiménez-Ballvé A, García-García-Esquinas M, Salsidua-Arroyo O et al (2016) Prognostic value of metabolic tumour volume and total lesion glycolysis in ${ }^{18} \mathrm{~F}$-FDG PET/CT scans in locally advanced breast cancer staging. Rev Esp Med Nucl Imagen Mol 35(6):365-372

19. Suzuki H, Nishio M, Nakanishi H et al (2016) Impact of total lesion glycolysis measured by (18)F-FDG-PET/CT on overall survival and distant metastasis in hypopharyngeal cancer. Oncol Lett 12(2):1493-1500. https://doi. org/10.3892/ol.2016.4765

20. Zhou M, Chen Y, Huang H et al (2016) Prognostic value of total lesion glycolysis of baseline F-fluorodeoxyglucose positron emission tomography/ computed tomography in diffuse large B-cell lymphoma other factors including MTV, National Comprehensive Cancer Network International Prognostic Ind. Oncotarget 7(50):83544-83553

21. Ogawa S, Itabashi M, Kondo C et al (2015) Prognostic value of total lesion glycolysis measured by $18 \mathrm{~F}-\mathrm{FDG}-\mathrm{PET} / \mathrm{CT}$ in patients with colorectal cancer. Anticancer Res 35(6):3495-3500
22. Ziai P, Hayeri MR, Salei A et al (2016) Role of optimal quantification of FDG PET imaging in the clinical practice of radiology. Radiographics 36(2):481-496. https://doi.org/10.1148/rg.2016150102

23. Jiménez-Ballvé A, García García-Esquinas M, Salsidua-Arroyo, et al (2016) Prognostic value of metabolic tumor volume and total lesion glycolysis in 18F-FDG PET/CT scans in locally advanced breast cancer staging. Revista Española de Medicina Nuclear e Imagen Molecular (Engl Ed) 35(6):365-372

24. Önner H, Canaz F, Dinçer M et al (2019) Which of the fluorine-18 fluorodeoxyglucose positron emission tomography/computerized tomography parameters are better associated with prognostic factors in breast cancer? Medicine 98(22):e15925. https://doi.org/10.1097/MD.0000000000 015925

25. An YS, Kang DK, Jung Y et al (2017) Volume-based metabolic parameter of breast cancer on preoperative 18F-FDG PET/CT could predict axillary lymph node metastasis. Medicine 96(45):e8557

26 Fathinul Fikri A, Lau W (2010) An intense F-FDG pulmonary microfocus on PET without detectable abnormality on CT: A manifestation of an iatrogenic FDG pulmonary embolus. Biomed Imaging Interv J. 6(4):e37. https://doi.org/10.2349/biij.6.4.e37

27. Azmi NHM, Suppiah S, Liong CW, Noor NM, Said SM, Hanafi MH, Kaewput C, Saad FFA, Vinjamuri S (2018) Reliability of standardized uptake value normalized to lean body mass using the liver as a reference organ, in contrast-enhanced 18F-FDG PET/CT imaging. Radiat Phys Chem 147:35-39

\section{Publisher's Note}

Springer Nature remains neutral with regard to jurisdictional claims in published maps and institutional affiliations.

\section{Submit your manuscript to a SpringerOpen ${ }^{\circ}$ journal and benefit from:}

- Convenient online submission

- Rigorous peer review

- Open access: articles freely available online

- High visibility within the field

- Retaining the copyright to your article

Submit your next manuscript at $\boldsymbol{\nabla}$ springeropen.com 